\title{
Development and validation of a rapid method for the detection of latrunculol $A$ in plasma
}

\author{
Jiajiu Shaw • Frederick A. Valeriote • Joseph Media • \\ Tyler A. Johnson • Taro Amagata • Karen Tenney • \\ Phillip Crews
}

Received: 26 October 2009/Revised: 30 November 2009/Accepted: 4 December 2009/Published online: 31 December 2009

(C) The Author(s) 2009. This article is published with open access at Springerlink.com

\begin{abstract}
Latrunculol A is a recently discovered 6,7dihydroxy analog of the potent actin inhibitor latrunculin A. Latrunculol A has exhibited greater cytotoxicity than latrunculin A against both murine and human colon tumor cell lines in vitro. Currently, there are no reports regarding the bioavailability of latrunculol A in vivo. This study was undertaken as a prelude to pharmacokinetic assessments and it is the first work where bioavailability of latrunculol A was studied. In the present work, a simple plasma preparation and a rapid HPLC method have been developed. Mouse plasma containing latrunculol A was first treated by acetonitrile and then centrifuged at $14,000 \mathrm{rpm}$ at $4{ }^{\circ} \mathrm{C}$ for $25 \mathrm{~min}$. The supernatant was injected in an HPLC system comprising a Waters Symmetry $\mathrm{NH}_{2}$ column, a mobile phase of acetonitrile/water $(95 / 5, v / v)$, a flow rate of $1.0 \mathrm{~mL} / \mathrm{min}$, at $220 \mathrm{~nm}$. The method was validated by parameters including a good linear correlation, a limit of quantification of $9 \mathrm{ng} / \mathrm{mL}$, and a good precision with a coefficient variation of $1.65,1.86$, and $1.26 \%$ for 20,400 , and $800 \mathrm{ng} / \mathrm{mL}$, respectively. With this simple method, excellent separation and sensitivity of latrunculol A are achieved, thus allowing a rapid analysis of the plasma samples for absorption, distribution, and metabolism studies.
\end{abstract}

Keywords Latrunculins · Latrunculol A .

Anti-actin activity $\cdot$ HPLC analysis · Bioavailability

\author{
J. Shaw $(\bowtie) \cdot$ F. A. Valeriote $\cdot$ J. Media \\ Henry Ford Health System, \\ Detroit, MI 48202, USA \\ e-mail: jiajiushaw@gmail.com
}

T. A. Johnson · T. Amagata $\cdot$ K. Tenney $\cdot$ P. Crews

Department of Chemistry and Biochemistry and Institute

for Marine Sciences, University of California,

Santa Cruz, CA 95064, USA
The latrunculin class of bioactive small molecules continues to command attention as their chemical structures and biological properties have been explored for nearly three decades [1]. The octaketide macrolide, latrunculin A [1], represents one lead member of this class, and a relatively small assemblage of marine sponges and nudibranchs constitute the exclusive source of such compounds in nature [2]. The sustained interest in this class is primarily due to the pronounced anti-actin activity of the latrunculins [3-5]. In spite of reports that latrunculin analogs possess in vitro antitumor activity [2, 6-9], there continues to be reduced interest in developing such compounds as therapeutic leads for solid tumors [2]. As an important counterpoint, a study exists showing a positive in vivo therapeutic efficacy for latrunculin A at a dose of $0.3 \mathrm{mg} / \mathrm{kg}$ using a sc-implanted A549 lung tumor xenograft mouse model which yielded a survival ratio of $146 \%$ for (number of survivors in treated group)/(number of survivors in control group) although the survivors were not completely tumor-free [10]. As another encouraging observation, latrunculin A also shares a similar carbon skeleton with the recently approved anticancer agent Ixempra $^{\mathrm{TM}}$ (ixabepilone) [11], a semi-synthetic analog of the natural product epitholone B [12] (Fig. 1).

The preceding analysis and the rich representation of analogs of latrunculin A in our repository prompted this study to further assess the latrunculin pharmachophore as an anticancer therapeutics lead. We recently reported that latrunculol A exhibited greater in vitro inhibition against murine (colon 38) and human (HCT-116) colon tumor cell lines vs. latrunculin A [2]. Since little is known about the bioavailability of latrunculol A, the fundamental next step consists of a pharmacokinetic assessment. Described below is a validated method to determine latrunculol $\mathrm{A}$ in mouse plasma by a simple extraction of plasma samples followed by an isocratic HPLC analysis with UV detection. 
Fig. 1 Structures of latrunculin A, ixabepilone, epitholone B, and latrunculol $\mathrm{A}$

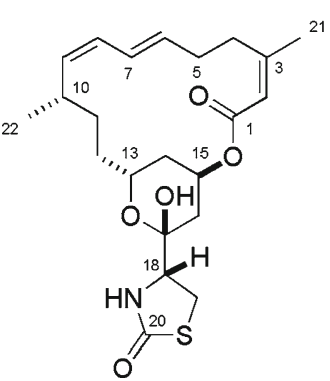

latrunculin $\mathrm{A}$

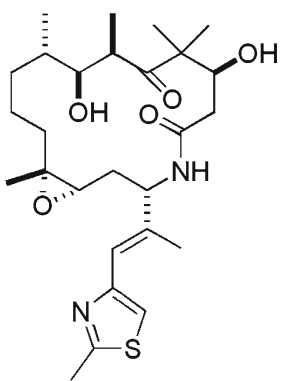

ixabepilone<smiles>C/C(=C\c1csc(C)n1)[C@H](CCC(C)(C)CCC[C@@H](C)C(O)C(C)C1C(=O)CC(O)C(C)(C)C1=O)OC(=O)CO</smiles>

epitholone B

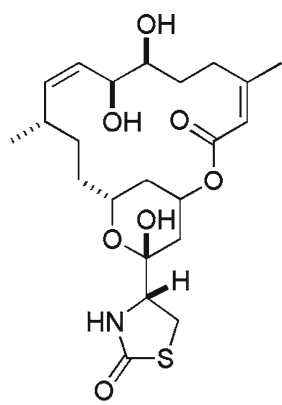

latrunculol A
Since there are no reports regarding the bioavailability of latrunculol $\mathrm{A}$, two mice per time point were used to assess the validity of the method in order to further the preclinical development of latrunculol A.

\section{Experimental}

Instruments A Waters Alliance HPLC system [including a Waters 2690 Separations Module, a Waters 2996 Photodiode Array Detector, a Waters Symmetry $\mathrm{NH}_{2}$ reversedphase column $(3.9 \times 300 \mathrm{~mm}, 10 \mu \mathrm{m})$, and the Waters Empower software] (Milford, Massachusetts, USA) was used in this study for the determination of latrunculol A. A Beckman Coulter Allegra 21R Centrifuge (Fullerton, California, USA) was used to prepare the plasma and plasma samples for HPLC injection.

Reagents Latrunculol A (purity 98.97\%) was isolated as previously described [2], and all solvents were HPLC-grade and obtained from Burdick \& Jackson (Muskegon, Michigan, USA).

Preparation of plasma and plasma samples Blood samples from $\mathrm{C} 57$ female mice were collected by cardiac puncture using a $1-\mathrm{mL}$ syringe (with a 25 -gauge needle) coated with heparin. Once the maximum amount of blood was collected, it was transferred to a $1.5-\mathrm{mL}$ conical centrifuge tube and centrifuged at $12,000 \mathrm{rpm}$ (equivalent to $14,160 \times \mathrm{g}$ ) at $4{ }^{\circ} \mathrm{C}$ for $10 \mathrm{~min}$. Plasma was then transferred and stored in a freezer at $-20{ }^{\circ} \mathrm{C}$. To prepare individual spiked standards, plasma was thawed for $30 \mathrm{~min}$, different concentrations of latrunculol A were added to $200 \mu \mathrm{L}$ of

Table 1 Concentration of latrunculol A in plasma at 1, 4, and $6 \mathrm{~h}$ (two mice per time point)

\begin{tabular}{lrrr}
\hline & $1 \mathrm{~h}$ & $4 \mathrm{~h}$ & \multicolumn{1}{c}{$6 \mathrm{~h}$} \\
\hline $\begin{array}{c}\text { Conc (ng/mL) from 2 } \\
\text { individual mice }\end{array}$ & 451,431 & 121,387 & 86,363 \\
$\begin{array}{c}\text { Average conc (ng/mL) } \\
\text { Perage }\end{array}$ & 441 & 254 & 225 \\
\hline
\end{tabular}

plasma samples and acetonitrile was added to each a total volume of $1 \mathrm{~mL}$, vortexed for $1 \mathrm{~min}$, and centrifuged at $14,000 \mathrm{rpm}$ (equivalent to $19,280 \times \mathrm{g}$ ) at $4{ }^{\circ} \mathrm{C}$ for $25 \mathrm{~min}$. The supernatant was then used for HPLC analysis. To prepare plasma samples, $4 \times(v / v)$ of acetonitrile was added to each plasma sample (typically, $800 \mu \mathrm{L}$ acetonitrile was added to $200 \mu \mathrm{L}$ plasma), vortexed for $1 \mathrm{~min}$, and centrifuged the same way as the spiked plasma standards. The supernatant was then used for HPLC analysis.

HPLC procedure Latrunculol A in the eluted fraction was determined using a Waters Symmetry $\mathrm{NH}_{2}$ column $(3.9 \times$ $300 \mathrm{~mm}$ ) with a $10-\mu \mathrm{m}$ particle size and a pre-column of the same material as the stationary phase. The injection volume was $20 \mu \mathrm{L}$. The temperature of the column oven was room temperature. The mobile phase was acetonitrile/ water $(95 / 5, v / v)$. The flow rate was $1 \mathrm{~mL} / \mathrm{min}$. The lack of a maximum absorption in the UV range was overcome by the successful use of a $220 \mathrm{~nm}$ detection wavelength to analyze murine blood samples spiked with latrunculol A. The results of the analysis are expressed in nanograms of latrunculol A per milliliter of plasma.

Calibration curve A stock solution of $1,000 \mathrm{ng} / \mathrm{mL}$ was prepared in acetonitrile. The calibration curve was obtained with pooled mouse plasma spiked with known amounts of the stock solution. The analyte was extracted according to the

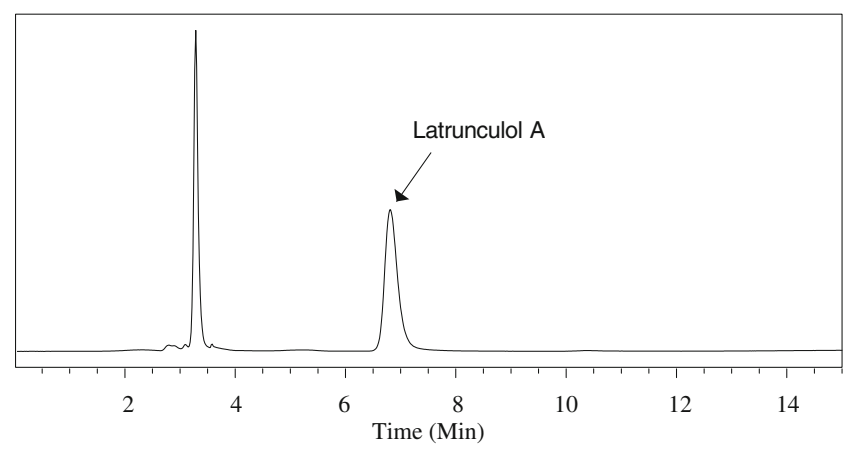

Fig. 2 A typical chromatogram of $20 \mathrm{ng} / \mathrm{mL}$ latrunculol A (spiked plasma) at $220 \mathrm{~nm}$. Acetonitrile/water $(95 / 5, v / v)$ was used as the mobile phase and the flow rate was $1 \mathrm{~mL} / \mathrm{min}$. The peak at $3.4 \mathrm{~min}$ resulted from plasma (verified by a plasma control) 
Table 2 Assay of a latrunculol A sample (300 ng/mL) over a period of 3 days

\begin{tabular}{lc}
\hline Intra-day assay & Results $(\mathrm{ng} / \mathrm{mL})$ \\
\hline Day 1, morning & 300.90 \\
Day 1, afternoon & 301.54 \\
Day 1, night & 301.19 \\
Avg \pm SD & $301.21 \pm 0.32$ \\
RSD (\%) & 0.11 \\
Avg from Day 1 & 301.21 \\
& \\
Day 2 & 299.83 \\
Day 3 & 298.97 \\
Avg \pm SD & $300.00 \pm 1.13$ \\
RSD (\%) & 0.38 \\
\hline
\end{tabular}

protocol described above. The calibration curve was obtained by plotting the peak area of latrunculol A against its concentration in seven spiked plasma standards $(1,000,800,400,200$, 100,20 , and $10 \mathrm{ng} / \mathrm{mL}$ ) and performing a linear regression.

Animal study Latrunculol A was administered i.p. to C57 female mice at $3.1 \mathrm{mg} / \mathrm{kg}$ (injection of $0.25 \mathrm{~mL}$ of $0.25 \mathrm{mg} / \mathrm{mL}$ of latrunculol $\mathrm{A}$ in saline, containing $5 \%$ DMSO and 5\% cremophor/propylene glycol 60/40, v/v); the animals were sacrificed at 1,4 , and $6 \mathrm{~h}$ after drug administration. Blood was taken by cardiac puncture and transferred to a tube containing heparin as anticoagulant. Plasma was obtained by centrifugation, and the analyte was extracted using the procedure described above. Animal treatment was in full accordance with the Institutional
Animal Care and Use Committee (IACUC) Guidelines for the care and management of laboratory animals.

\section{Results and discussion}

The data gathered allows detection of latrunculol A over a wide range of concentrations. We also observed that it is stable in plasma for up to $72 \mathrm{~h}$. The method developed here was validated according to the U.S. Pharmacopeia [13] and the analytical performance parameters considered were selectivity (specificity), linearity, accuracy, precision, sensitivity, and ruggedness. To assess the validity of the technique, C57 female mice (average weight $20 \mathrm{~g}$ ) were injected i.p. with latrunculol A (3.1 mg/kg). Blood samples from two mice were taken by cardiac puncture at 1,4 , and $6 \mathrm{~h}$, processed, and analyzed as described in the "Experimental" section. The results shown in Table 1 indicate that a significant amount of latrunculol A was found in the plasma over the 6-h testing period.

The key analytical details pertaining to the method described above require additional comments.

The six parameters used to validate the method are as follows: (1) Selectivity, latrunculol A was quantified at $220 \mathrm{~nm}$ wherein no significant interfering peaks were observed. A typical chromatogram at this wavelength shown in Fig. 2 indicated that latrunculol A was well resolved and free from interference peaks. The use of a photodiode array detector allowed the confirmation of the identity of the chromatographic peak not only by its retention time but also by its spectrum. (2) Linearity, calibration curves of latrunculol A were prepared to
Table 3 Assay results of three samples with known concentrations $(100,300$, and $600 \mathrm{ng} / \mathrm{mL})$ under various HPLC conditions

\begin{tabular}{lcccc}
\hline & $\begin{array}{c}\text { Change } \\
\text { level }\end{array}$ & Sample 1 & Sample 2 & Sample 3 \\
\hline $\begin{array}{l}\text { Effect of mobile phase variation on assay } \\
\text { (ng/mL) }\end{array}$ & & & & \\
Acetonitrile (\%) & & & & \\
94 & -1 & 99.82 & 300.15 & 600.01 \\
95 & 0 & 99.72 & 301.94 & 599.47 \\
96 & +1 & 100.01 & 301.61 & 599.25 \\
Avg \pm SD & & $99.85 \pm 0.15$ & $301.23 \pm 0.95$ & $599.58 \pm 0.39$ \\
RSD (\%) & & 0.15 & 0.32 & 0.07 \\
& & & & \\
Effect of flow rate variation on assay (ng/mL) & & & & \\
Flow rate (mL/min) & -0.1 & 100.07 & 300.04 & 600.41 \\
0.9 & 0 & 99.72 & 301.94 & 599.47 \\
1.0 & +0.1 & 99.67 & 301.52 & 598.00 \\
1.1 & & $99.82 \pm 0.22$ & $301.17 \pm 1.00$ & $599.29 \pm 1.21$ \\
Avg \pm SD & & 0.22 & 0.33 & 0.20 \\
RSD (\%) & & &
\end{tabular}


determine the linearity of the method over the range of 10 $1,000 \mathrm{ng} / \mathrm{mL}$. Integrated peak areas were plotted against analyte concentration, and linear regression was performed by the least-squares method. The calibration curve generated using plasma as matrix showed a square of correlation coefficient of 0.9992. (3) Accuracy, the accuracy of the analytical method was determined by application of the method to analytes of known concentrations. Three spiked plasma samples $(100,300$, and $600 \mathrm{ng} / \mathrm{mL})$ were prepared and analyzed and the assay results were $99.72,301.94$, and $599.47 \mathrm{ng} / \mathrm{mL}$, indicating a recovery of $99.72 \%, 100.67 \%$, and $99.92 \%$ for these samples. Therefore, the method is accurate. (4) Precision, the precision of the analytical method was determined by analyzing three homogeneous samples of plasma spiked with three levels of latrunculol A (20,400, and $800 \mathrm{ng} / \mathrm{mL}$, respectively) in six replicates. Peak areas were considered for the determination. The precision, expressed as the coefficient of variation $(\mathrm{CV})$, was $1.65 \%, 1.86 \%$, and $1.26 \%$ for each individual sample. These values were lower than those normally acceptable in the U.S. Pharmacopeia [13] indicating that the method is precise. (5) Sensitivity, the limit of detection (LOD) and the limit of quantification (LOQ) were obtained by first injecting six replicates of a sample at $5 \mathrm{ng} / \mathrm{mL}$; the standard deviation (StDev) was multiplied by 3 and by 10 and the calibration curve was used to obtain the LOD and LOQ, respectively. At $220 \mathrm{~nm}$, the LOD for latrunculol A was $3 \mathrm{ng} / \mathrm{ml}$ and the LOQ was $9 \mathrm{ng} / \mathrm{ml}$. (6) Ruggedness (robustness), ruggedness was shown by assaying a spiked plasma sample with known concentration $(300 \mathrm{ng} / \mathrm{mL})$ on three consecutive days employing the corresponding linearity curve generated on the day the sample was assayed. As shown in Table 2, intra- and inter-day assay results of a particular sample are essentially the same, indicating an acceptable ruggedness of the method for intra- and inter-day assay studies. In addition, three spiked samples $(100,300$, and $600 \mathrm{ng} / \mathrm{mL})$ were analyzed using slightly modified mobile phases and different flow rates. As shown in Table 3, when acetonitrile/water ratio was changed to $94 / 6$ or $96 / 4$ as compared to the normal $95 / 5(v / v)$ ratio, no significant differences were observed in the assay results as indicated by the relative standard deviation (RSD). When the flow rate was reduced/ increased to $0.9 / 1.1 \mathrm{~mL} / \mathrm{min}$ as compared to the normal $1 \mathrm{~mL} / \mathrm{min}$, the assay results were essentially the same. These assay results further indicate that the present method is rugged with respect to minor changes of the mobile phase or the flow rate.
In summary, we have shown that each of the six parameters discussed above provides a good basis for further bio-evaluation of latrunculin A. The method described herein is suitable for analyzing plasma samples of latrunculol A. Compared with conventional methods, our protocol has the advantage that time-consuming procedures (such as solid-phase extraction, drying, and reconstitution) are not necessary. Until now, no data have been published concerning absorption, bioavailability, and tissue distribution of latrunculol A. We have successfully developed a simple method to determine latrunculol A in plasma, and we have also detected for the first time the absorption of this compound in mouse blood. Further experiments will now be possible to evaluate and understand the pharmacokinetics and efficacy of latrunculol A in mice.

Acknowledgment This work was supported by NIH/NCI grant CA47135.

Open Access This article is distributed under the terms of the Creative Commons Attribution Noncommercial License which permits any noncommercial use, distribution, and reproduction in any medium, provided the original author(s) and source are credited.

\section{References}

1. Spector I, Shochet NR, Kashman Y, Groweiss A (1983) Science 219:493-495

2. Amagata T, Johnson TA, Cichewicz RH, Tenney K, Mooberry SL, Media J, Edelstein M, Valeriote FA, Crews P (2008) J Med Chem 51:7234-7242

3. Ayscough KR, Stryker J, Pokala N, Sanders M, Crews P, Drubin DG (1997) J Cell Biol 137:399-416

4. Hoye TR, Ayyad SN, Eklov BM, Hashish NE, Shier WT, El Sayed KA, Hamann MT (2002) J Am Chem Soc 124:74057410

5. Folmer F, Houssen WE, Scott RH, Jaspars M (2007) Curr Opin Drug Disc 10:145-152

6. Hayot C, Debeir O, Van Ham P, Van Damme M, Kiss R, Decaestecker C (2006) Toxicol Appl Pharmacol 211:30-40

7. ElSayed KA, Youssef DT, Marchetti D (2006) J Nat Prod 69:219-23

8. Ahmed SA, Odde S, Daga PR, Bowling JJ, Mesbah MK, Youssef DT, Khalifa SI, Doerksen RJ, Hamann MT (2007) Org Lett 9:4773-4776

9. ElSayed KA, Khanfar MA, Shallal HM, Muralidharan A, Awate B, Youssef DTA, Liu Y, Zhoo YD, Nagle DG, Shah G (2008) J Nat Prod 71:396-402

10. Longley RE, Mcconnell OJ, Essich E, Harmody D (1993) J Nat Prod 56:915-920

11. Bailly C (2009) Biochem Pharmacol 77:1447-1457

12. Bollag DM, Mcqueney PA, Zhu J, Hensens O, Koupal L, Liesch J, Goetz M, Lazarides E, Woods CM (1995) Cancer Res 55:23252333

13. The United State Pharmacopoeia (2000) USP XXIV 